\title{
Dehydroxylation kinetics of lizardite
}

\author{
ROY TRITTSCHACK* and BERNARD GROBÉTY \\ Department of Geosciences, University of Fribourg, Chemin du Musée 6, 1700 Fribourg, Switzerland \\ *Corresponding author, e-mail: roy.trittschack@unifr.ch
}

\begin{abstract}
The thermally induced dehydroxylation of lizardite and its phase transformation to forsterite were studied by hightemperature X-ray diffraction (HT-XRD), thermogravimetry (TGA) and Fourier-transformed infrared spectroscopy (FTIR). Primary sample characteristics like chemical composition and crystallographical structure were determined by combined (HR)TEM-EDX, electron-microprobe analyses (EMPA) as well as conventional X-ray diffraction (XRD). Isothermal HT-XRD and non-isothermal TGA data were treated with the classical Avrami-Erofe'ev method and more advanced isoconversional methods in order to obtain kinetic data of a multi-step decomposition reaction. A highly precise activation energy $E_{a}$ versus reaction progress $(\alpha)$ dependency based on non-isothermal TGA data of lizardite is provided and associated mechanisms are discussed. Here, the main focus is on recently published $a b$ initio calculations from the phase transformation of other phyllosilicates. Moreover, the calculated overall apparent activation energy is compared with discrepant data from the literature and discussed. Especially, the usability of overall activation energies of multi-step decomposition reactions is critically discussed. The presented and discussed reaction steps of water formation from different hydroxyl species in lizardite can be used to improve $a b$ initio calculations, especially the pre-selection of reacting hydroxyl species in hydrous sheet like minerals.
\end{abstract}

Key-words: lizardite dehydroxylation, model-free kinetics, in situ high-temperature X-ray diffraction.

\section{Introduction}

Lizardite $\mathrm{Mg}_{3} \mathrm{Si}_{2} \mathrm{O}_{5}(\mathrm{OH})_{4}$ is a trioctahedral 1:1 phyllosilicate and, together with chrysotile and antigorite, is the most prominent representative of the serpentine mineral group. The general building blocks of these trioctahedral serpentine minerals are tetrahedrally coordinated silicate layers $(\mathrm{T})$ and octahedrally coordinated brucite-like layers $(\mathrm{O})$, which are connected into TO sheets. In the case of lizardite, these TO-sheets are flat and stacked along the $c$ axis. Crystal-structure refinements on suitable crystals by Brigatti et al. (1997); Mellini (1982) and Mellini \& Zanazzi (1987) revealed three polytypes $2 \mathrm{H}_{2}, 1 \mathrm{~T}$ and $2 H_{1}$. However, natural samples often consist of an inseparable mixture of these polytypes and some minor amounts of chrysotile and/or antigorite.

Serpentinites are important water-bearing rocks of the oceanic lithosphere and underlying mantle. Their dehydration is responsible for fractional melting in the overlying mantle wedge and may be the trigger for deep-seated earthquakes (Ulmer \& Trommsdorff, 1995). Dehydration has also been proposed for the disposal of chrysotile asbestos (Gualtieri \& Tartaglia, 2000). Astonishingly, the mechanisms of these dehydration reactions are only poorly understood. The structural diversity of the serpentine minerals, i.e. flat layers in lizardite but bent layers in antigorite and chrysotile, is ideally suited to explore the influence of mesoscale structure on dehydration. The cylindrical structure of chrysotile may be an ideal example to study basic aspects of reactions in non-translational multiwall nanotube phases.

Dehydroxylation kinetics of serpentine minerals have been extensively studied by thermogravimetric analysis (e.g. Brindley et al., 1963a and b; Weber \& Greer, 1965) and in recent times by X-ray powder diffraction (XRPD) techniques (Cattaneo et al., 2003). In these investigations, kinetic and mechanistic data were derived from experiments done under isothermal conditions and treated by classical kinetic methods developed by Avrami (1939, 1940, 1941), Erofe'ev (1946) and Johnson \& Mehl (1939) or by the "time to a given fraction" (TGF) method (Burke, 1965). Hancock \& Sharp (1972) used these principles to extract physical interpretation from a single reaction-dependent constant ("reaction order") alone. A comprehensive overview of these methods including various case studies is given by Bamford \& Tipper (1980). A critical appraisal discussing the limitations and shortcomings in the classic treatment of solid-state kinetics has been given by Galwey (2004).

Isothermal experiments have some major disadvantages (Vyazovkin \& Wight, 1997). It is not possible to determine time resolved (reaction progress, $\alpha$ ) activation energies by such methods, but only values averaged over a certain reaction duration. It is, therefore, almost impossible to 
extract mechanistic information from such data, except for reactions for which the same reaction step is rate-determining for the entire duration of the reaction (Vyazovkin \& Wight, 1997). The difficulties in the interpretation of isothermal experiments begin with the heating up of the sample, which inevitably leads to an inaccurate determination of the zero time $t_{\alpha=O}$ of an experiment. This might explain the large spread in reported activation energy determined by the isothermal method. The TGF method has the advantage to indicate a change of the activation energy with time. But the activation energies are always integrated over time and volume of the sample. Non-isothermal methods give reaction progress resolved activation energies. The value, however, is still integrated over the entire reaction volume. Each change indicates that either the contribution of an individual parallel step changes or that a new reaction step contributes to the overall rate. In the case where several parallel and/or sequential reaction steps are rate-determining, the value again represents an average of the activation energies of the individual steps.

This study presents kinetic data for the dehydroxylation of lizardite derived from non-isothermal isoconversional measurements obtained from thermogravimetry (Friedman, 1964; Vyazovkin, 2000) and compares them with data from conventional isothermal results obtained from in situ high-temperature X-ray powder diffraction. The highly resolved datasets will be discussed in terms of mechanisms and compared with recent $a b$ initio calculations of dehydroxylation induced phase-transformations in pyrophyllite (Molina-Montes et al., 2008a and b) and kaolinite (White et al., 2010). These data serve as starting point for future dehydration experiments on chrysotile and antigorite.

\section{Experimental methods}

The sample under study was a pale-green, in parts translucent, lizardite from the collection of the ETH Zurich without any details of composition or locality. It was crushed by hand and translucent pieces were then manually separated to exclude magnetite inclusions present in the sample. The fragments were subsequently milled with a vibratory disk mill for $45 \mathrm{~s}$. Part of the powder was sieved to obtain a fraction $\leq 63 \mu \mathrm{m}$. A qualitative phase analysis was performed by X-ray powder diffraction using a Philips PW1800 diffractometer with conventional BraggBrentano geometry, operated with a $\mathrm{Cu} K \alpha$ tube $(40 \mathrm{kV}$ to $40 \mathrm{~mA}$ ) and equipped with a variable divergence slit. The diffraction patterns were recorded in step scan mode $\left(0.02{ }^{\circ} 2 \Theta /\right.$ step, $\left.5 \mathrm{~s} / \mathrm{step}\right)$ in the range of $5-100{ }^{\circ} 2 \Theta$.

The samples were structurally characterised by Transmission Electron Microscopy (TEM) with a Philips CM200 TEM (200 kV, CSEM Neuchâtel). HRTEM imaging and selected-area electron diffraction (SAED) were carried out on powdered samples deposited on carboncoated copper grids and a carbon-coated ion-milled lizardite sample prepared from a conventional thin section (BAL-TEC Res100 ion mill, Ar, 4 kV).
The chemical composition was determined using a JEOL JXA-8200 electron microprobe $(15 \mathrm{kV}$, beam current: $20 \mathrm{nA}$, beam diameter: $10 \mu \mathrm{m})$ at the University of Bern. Calibration was done using forsterite $(\mathrm{Mg})$, anorthite (Al, Ca), wollastonite ( $\mathrm{Si})$, ilmenite (Ti), eskolaite $(\mathrm{Cr})$, tephroite $(\mathrm{Mn})$, almandine $(\mathrm{Fe})$ and bunsenite (Ni). Primary data were corrected by the PhiRhoZ-method.

Reaction rates were determined from in situ high-temperature X-ray powder diffraction patterns, which were recorded in air and under controlled $\mathrm{N}_{2}$ atmosphere $(200 \mathrm{ml} / \mathrm{min})$ with a Philips PW1830 diffractometer (Bragg-Brentano geometry, $\mathrm{Cu} K \alpha$ radiation, $40 \mathrm{kV}$ to $40 \mathrm{~mA}$ ) equipped with a high temperature vacuum camera (Paar Physica HTK 10). The powdered sample was deposited on a $0.7 \mathrm{~mm}$ thick $1737 \mathrm{~F}$ low alkali glass holder, which itself was placed onto a platinum strip with an attached $\mathrm{Pt}-10 \% \mathrm{RhPt}$ thermocouple in the centre of the camera. Temperature calibration was performed using the melting points of $\mathrm{NaNO}_{3}\left(T_{\mathrm{M}}=\right.$ $\left.306{ }^{\circ} \mathrm{C}\right), \mathrm{Ba}\left(\mathrm{NO}_{3}\right)_{2}\left(T_{\mathrm{M}}=592^{\circ} \mathrm{C}\right), \mathrm{KCl}\left(T_{\mathrm{M}}=790{ }^{\circ} \mathrm{C}\right)$ and $\mathrm{NaCl}\left(T_{\mathrm{M}}=801{ }^{\circ} \mathrm{C}\right)$. During data collection a divergence slit of $1^{\circ}$ and a receiving slit of $0.2 \mathrm{~mm}$ were used. The sample was heated at $550{ }^{\circ} \mathrm{C} / \mathrm{min}$ to keep the impact of the heating up cycle as small as possible. Because of peak overlap between lizardite and newly-formed olivine peaks, only the decrease of (001) lizardite reflections was analysed. The range between $12.25-14.00^{\circ} 2 \Theta$ was measured in step scan mode $\left(0.02^{\circ} 2 \Theta /\right.$ step, $5 \mathrm{~s} /$ step $)$. Data were collected between $600{ }^{\circ} \mathrm{C}$ and $660^{\circ} \mathrm{C}\left(10^{\circ} \mathrm{C}\right.$ increments $)$. The chosen temperatures are directly related to analytical requirements, i.e. acceptable measurement duration and a necessary (minimum) number of individual data points. The experiments lasted 2 h to 3 days and between 20 and 200 diffractograms were recorded for each temperature increment. A profile fitting function implemented in the Philips APD V3.6h software was used to fit measured peaks. The same data were also fitted with the automated Fit Single Peak (GaussAmp model) function of the OriginPro8 ${ }^{\circledR}$ software package to verify the relative integral intensity decrease.

Particle size distributions $(0.40-2000 \mu \mathrm{m})$ were determined with a LS230 laser diffraction particle size analyser by Beckman-Coulter at the EMPA Duebendorf/ Switzerland.

Fourier-transformed infrared powder spectra were recorded with a Bomem Hartmann \& Braun MB155 FTIR spectrometer (College of engineering and architecture, Fribourg) in the spectral range between 400 and $4000 \mathrm{~cm}^{-1}$ with a resolution of $4 \mathrm{~cm}^{-1}$. Noise reduction was achieved by stacking 30 scans. Measurements of thermally pre-treated samples were carried out on conventional $\mathrm{KBr}$ pellets, which were dried for at least $2 \mathrm{~h}$ at $130{ }^{\circ} \mathrm{C}$ to avoid additional $\mathrm{H}_{2} \mathrm{O}$ bands caused by sample moisture. Background spectra were acquired from samplefree $\mathrm{KBr}$ pellets.

Non-isothermal thermogravimetric analyses (TGA) using a Mettler-Toledo TGA/SDTA 851e device (College of engineering and architecture, Fribourg) were carried out under a constant $\mathrm{N}_{2}$ flux of $100 \mathrm{ml} / \mathrm{min}$. The AKTS Thermogravimetric software package was used for kinetic calculations (Friedman method). Powdered 
samples were placed in conventional corundum sample holders and heated at $1,2,4,8,12,16$ and $32{ }^{\circ} \mathrm{C} / \mathrm{min}$ from 25 to $800^{\circ} \mathrm{C}$. For all experiments sample weights between 10 and $13 \mathrm{mg}$ were used to avoid heat-transfer effects within the sample material. The weight variation between individual samples of one experimental run (seven samples) was less than $0.5 \mathrm{mg}$.

\section{Data extraction}

Integral peak intensities extracted from isothermal in situ high-temperature X-ray powder diffraction patterns (HTXRD) were converted to relative intensities $\left(I / I_{O}\right)$ and plotted as reaction progress $(\alpha$ in $\%) v s$. time $(t)$ curves. The first integral peak intensity measured immediately after reaching the temperature of interest was taken as zero time intensity $\left(I_{O}\right)$. The classical Avrami-Erofe'ev (Bamford \& Tipper, 1980) equation:

$\alpha=1-\exp (-k t)^{n}$

allows, after linearization

$-\ln \ln (1-\alpha)=n \ln k+n \ln t$

to extract the exponent $n$ from the slope, which for homogeneous reactions is indicative for the reaction mechanism, and the reaction rate $k$ from the intercept $n \ln k$ in corresponding $-\ln \ln (1-\alpha) v s$. $\ln t$ plots. A series of isothermal experiments deliver temperature-dependent reaction rates $k$, which are used to calculate the apparent activation energy $E_{a}$ on the base of the Arrhenius equation:

$k=A \times \exp \left(-\frac{E_{a}}{R T}\right)$

with the pre-exponential factor $A$, the gas constant $R$ and the absolute temperature $T$. The activation energy then can be extracted from $\ln k v s .1 / T\left[\mathrm{~K}^{-1}\right]$ plots, but the results only provide an average value over the entire reaction duration. Reaction order and activation energies for reactions involving solids can only be connected to specific reaction mechanisms if there is only one rate-determining step over the entire reaction duration.

The so-called "time to a given fraction" method (Burke, 1965) was used to calculate activation energies in dependency of the reaction progress, which may partly overcome the problem of averaged activation energy values of multistep processes. This method follows the isoconversional principle (Friedman, 1964) under isothermal conditions, i.e. the calculation of $E_{a}$ is, in contrast to the Avrami approach, independent of empirical rate functions. Instead the general differentiated rate equation serves as starting point: $\frac{\mathrm{d} \alpha}{\mathrm{d} t}=k \times f(\alpha)$

$\mathrm{d} t=k^{-1} \times f^{-1}(\alpha) \mathrm{d} \alpha$

The time, $t_{\alpha 1}$ required for a certain reaction progress $\alpha=\alpha_{1}$ can be obtained by integrating Equation (5) as follows

$t_{\alpha_{1}}=k^{-1} \int_{\alpha=0}^{\alpha=\alpha_{1}} f^{-1}(\alpha) \mathrm{d} \alpha$

Under the assumption of a constant $f(\alpha)$ within the investigated temperature interval, it is possible to calculate the activation energy for a certain reaction progress $E_{a \alpha}$ from the slopes of a set of plots $\ln t_{\alpha} v s .1 / T\left[\mathrm{~K}^{-1}\right]$. This method contains a major advantage compared to the Avrami treatment, namely changes of the activation energy as function of $\alpha$, i.e. changes in the rate-determining step, can be recognized. The equation makes only sense if the function describing the rate $f(\alpha)$ is the same over the entire reaction duration, which is usually not the case for solid-state reactions (Vyazovkin, 2008).

Non-isothermal data from TG analyses were treated with the differential isoconversional method (Friedman, 1964), starting with the customised general rate equation known from the isothermal case

$\frac{\mathrm{d} \alpha}{\mathrm{d} t}=f(\alpha) \times A \exp \left(-\frac{E_{a}}{R T(t)}\right)$

with

$\alpha=\frac{W_{0}-W_{t}}{W_{0}-W_{f}}$

where $W_{o}, W_{f}$ and $W_{t}$ are initial, final and time weights of the sample. Replacing the constant temperature term by the heating rate $\beta=\mathrm{d} T / \mathrm{d} t$ leads to

$\frac{\mathrm{d} \alpha}{\mathrm{d} t}=\frac{A}{\beta} \times \exp \left(-\frac{E_{a \alpha}}{R T(t)}\right) \times f(\alpha)$

The slopes $m$ in a plot $\ln (\mathrm{d} \alpha / \mathrm{d} t) v s .1 / T\left[\mathrm{~K}^{-1}\right]$ for a given reaction progress $\alpha$ gives the activation energy. A significant difference to the TGF method is that the derivation of the activation energy does not require a constant ratedetermining function over the entire reaction duration. This procedure has to be done for a series of different heating rates to guarantee the accuracy of the estimated $E_{a}-\alpha$ dependency (Vyazovkin, 2000). For the theoretical case that the rate-determining step changes simultaneously within the whole reaction volume, the activation energy of 
an individual step could be determined. Such a case would result in a stepwise evolution of $E_{a}$ with $\alpha$. But for solidstate reactions it is rather improbable. However, recently published data about the kinetics of Fe-oxidation/deprotonation in iron-rich phlogopites suggest a single rate-determining step for a narrow temperature range (Zema et al., 2010).

\section{Results}

\subsection{Characteristics of the sample material}

The X-ray diffraction patterns are close to the PDF reference pattern for lizardite $1 T$ (No 18-0779), which fit all observed peaks (Fig. 1). The broad and strongly asymmetric peaks indicate small coherently scattering domains due to small grain size and the presence of defects such as turbostratic stacking. Electron optical investigations have shown that the powdered sample consists of crystallites ranging from $40 \mathrm{~nm}$ to $1 \mu \mathrm{m}$ in size. The crushed powders used in the experiments consist of polycrystalline grains composed of such crystallites (Fig. 2). HRTEM studies on ion-thinned sections reveal a complex pattern of ordered lizardite intergrown with a minor amount of curled TO-layers (Fig. 3a) as already reported from other localities (Dódony \& Buseck, 2004). Stacking defects and intercalation of $1 T$ and $2 H$ polytypes are common (Fig. 3b).

The average of 50 individual electron microprobe analyses gave the following stoichiometric formula: $\left(\mathrm{Mg}_{2.84} \mathrm{Fe}_{0.04} \mathrm{Al}_{0.03}\right)\left(\mathrm{Si}_{2.02}\right) \mathrm{O}_{5}(\mathrm{OH})_{4.09}$ normalizing on 9 $(\mathrm{O}, \mathrm{OH})$ and calculating the hydroxyl content by difference. The water content obtained this way is $13.3 \mathrm{wt} \%$, which fits the water content calculated on the base of TGA quite well.

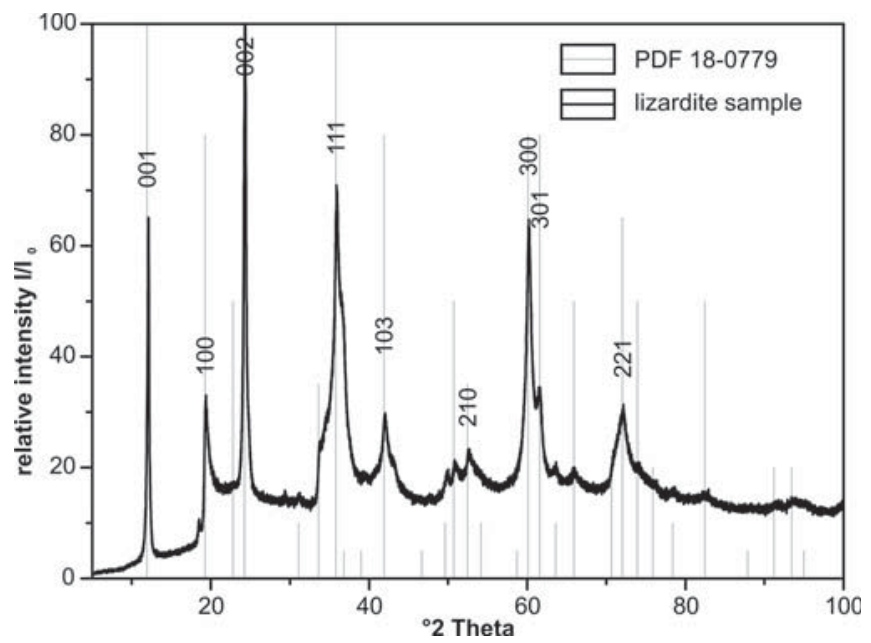

Fig. 1. XRD pattern of the LizZH1 sample fitting all peaks of the 180779 entry of the ICDD database.

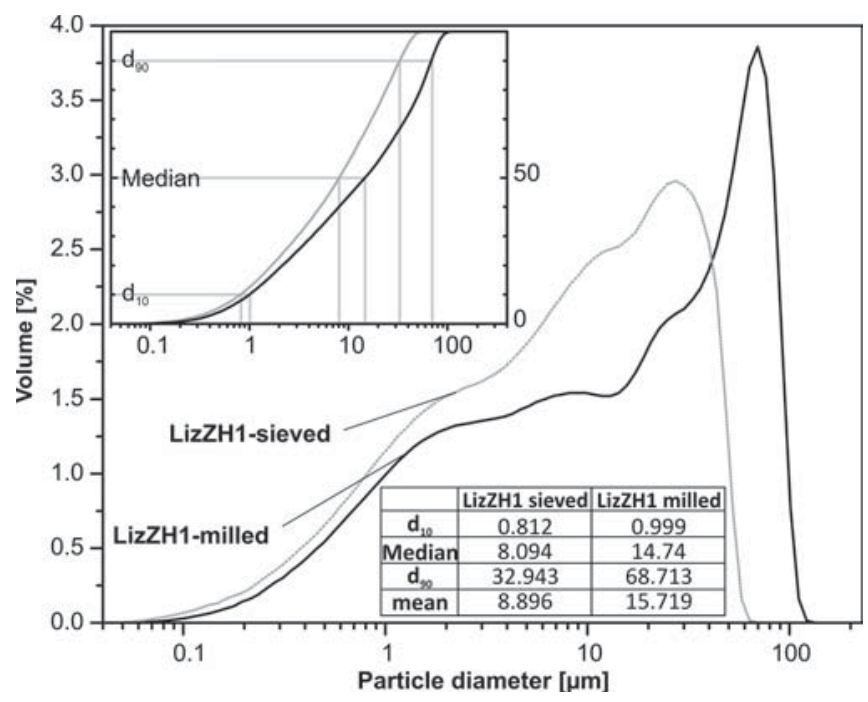

Fig. 2. Particle size distribution of the two investigated LizZH1 samples including d10, d90, mean and median parameters.
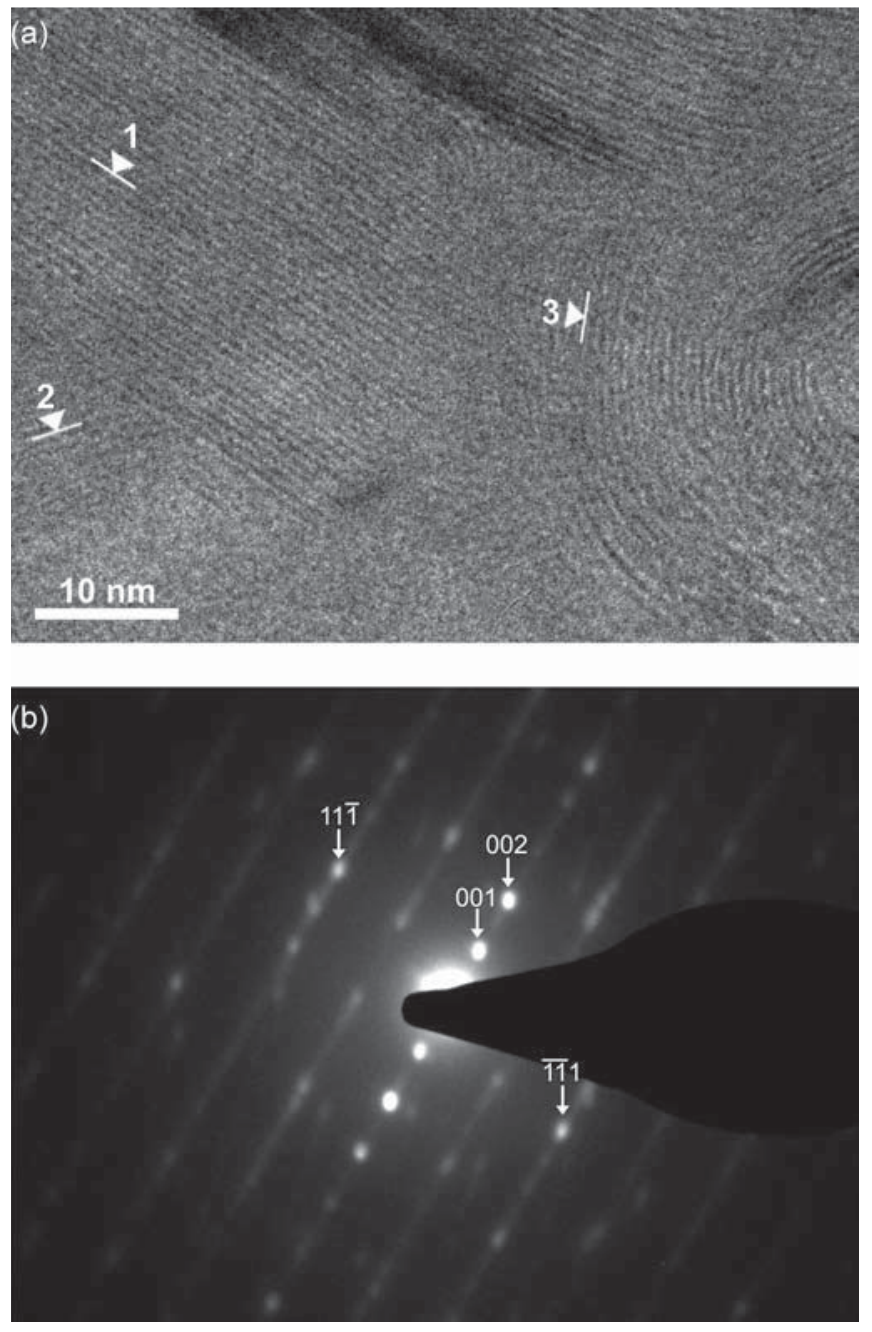

Fig. 3. (a) HRTEM image of ion-thinned lizardite with planar $1 T$ crystallites (1 and 2) and curled lizardite (3). (b) Representative [100] SAED pattern of lizardite. The strong reflections are compatible with the $1 T$ polytype. 


\subsection{Decomposition of lizardite}

The lizardite peaks in X-ray diffraction patterns decrease in intensity for annealing temperatures above $550^{\circ} \mathrm{C}$. After onset of the intensity reduction, a peak in the low-angle region of the diffractogram appears $\left(\sim 7.4^{\circ} 2 \Theta\right)$ as previously observed by McKelvy et al. (2004). After a delay, the duration of which is a function of temperature, forsterite peaks appear (Fig. 4). Simultaneously with the formation of the so-called " $\alpha$ " phase an increase in the background intensity is observed between 20 and $40^{\circ} 2 \Theta$. McKelvy et al. (2004) document the persistence of the increased background after disappearance of the " $\alpha$ " phase related low-angle reflection and all lizardite peaks followed by a subsequent growth of forsterite. Unfortunately, such a stepwise phase transformation was not reproduced during this study (Fig. 4).

The total weight loss measured by TG is between 12 and $13 \mathrm{wt} \%$, which corresponds relatively well to the stoichiometric amount of water released by the reaction. The temperature range in which water is released and the corresponding reaction rate are not fixed during non-isothermal conditions, as suggested by Viti (2010), but controlled by the chosen heating rate $\beta$. The relationship between heating rate and the temperature of maximum reaction rate $T_{\max }$ for the sieved and milled lizardite fractions is illustrated in Fig. 5 and were fitted by the general Hill equation (Seber \& Wild, 1989):

$$
T_{\max }^{\text {sieved }}=1410.155 \times \frac{\beta^{0.059}}{12.916^{0.059}+\beta^{0.059}}
$$

with $\mathrm{R}^{2}=0.999$

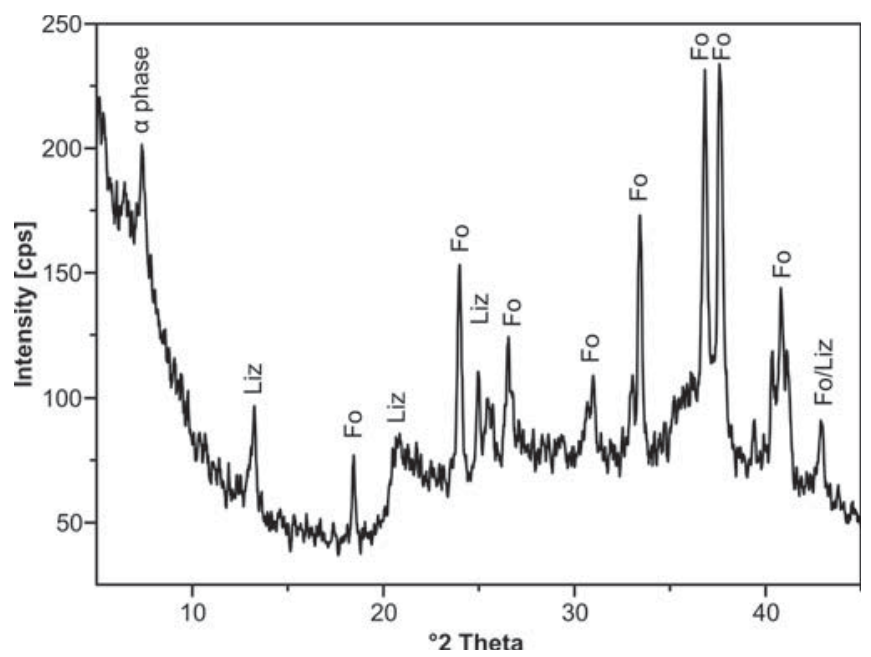

Fig. 4. High-temperature X-ray diffractogram of LizZH1 after $35 \mathrm{~h}$ at $600{ }^{\circ} \mathrm{C}$ showing the simultaneous occurrence of lizardite, forsterite and an intermediate " $\alpha$ ” phase.

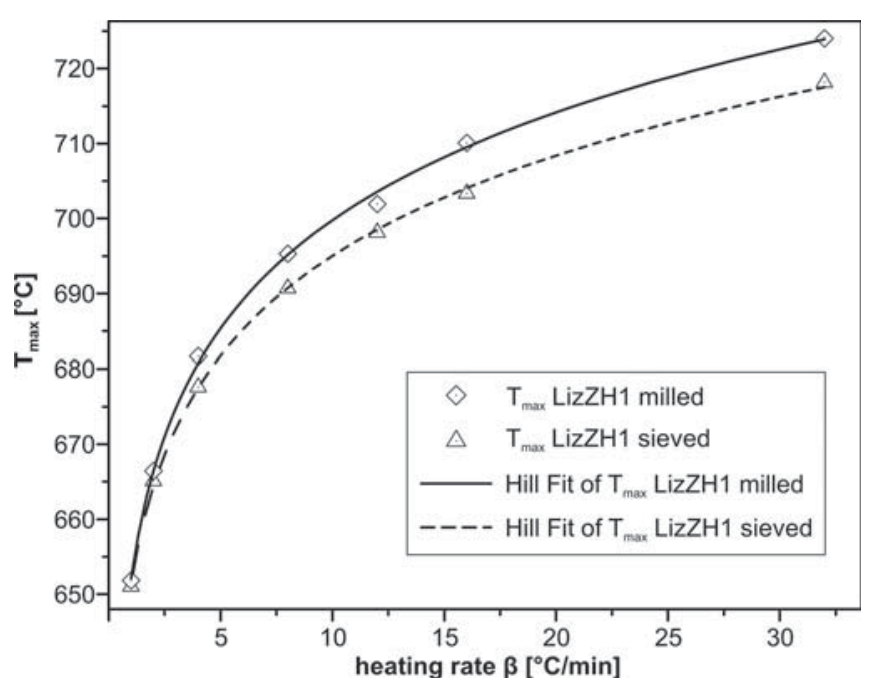

Fig. 5. Plot of $T_{\max }$ as a function of the heating rate $\beta$ of the lizardite subsamples based on non-linear curve fitting after the Hill equation.

$$
T_{\text {max }}^{\text {milled }}=1886.542 \times \frac{\beta^{0.044}}{\left(2.242 \times 10^{6}\right)^{0.044}+\beta^{0.044}}
$$

with $\mathrm{R}^{2}=0.999$

This dependency of water release rates and temperatures on heating rate has, therefore, to be considered when using non-isothermal TGA and equivalent data for unique discrimination of serpentine minerals.

FTIR data of thermally pre-treated and subsequently quenched powder samples show a general decrease of lizardite-related spectral features (Fuchs et al., 1998), i.e. of the $\mathrm{O}-\mathrm{H}$ stretching bands $\left(3600-3700 \mathrm{~cm}^{-1}\right)$, Si-O related bands $\left(900-1100 \mathrm{~cm}^{-1}\right.$ ) and $\mathrm{Mg}-\mathrm{O}$ respectively $\mathrm{Mg}-\mathrm{OH}$ bands (Table 1 and Fig. 6). The intensity decrease of the $\mathrm{Si}-\mathrm{O}$ bands, however, seems to be lower than for the $\mathrm{Mg}-\mathrm{OH}$ bands, although quantitative results are not possible on the base of individually prepared quenched FTIR samples. Similar bands reappear after a certain time, but the position and shape of them correspond to spectral features given for forsterite (Jolicoeur \& Duchesne, 1981). The first evidence of forsterite can already be observed in the spectra of Fig. 6d, although there hydroxyl groups remain present.

\subsection{Reaction kinetics}

Although the TGF and the non-isothermal data show that dehydration of lizardite is not controlled by a single reaction step, it is still interesting to compare the activation energy $E_{a}$ determined by the Avrami-Erofe'ev method with data available in the literature. Activation energies obtained by the Avrami-Erofe'ev method reach a value of $347 \pm 16 \mathrm{~kJ} / \mathrm{mol}$ (milled sample, air atmosphere) and 
Table 1. FTIR absorption bands $\left[\mathrm{cm}^{-1}\right]$ in primary lizardite (LizZH1 RT) and resulting forsterite (LizZH1 $650{ }^{\circ} \mathrm{C}$ ).

\begin{tabular}{|c|c|c|c|c|c|c|}
\hline Sample & $\begin{array}{c}\mathrm{OH} \\
\text { stretching } \\
\text { bands } \mathrm{s}^{\mathrm{a}, \mathrm{b}, \mathrm{c}}\end{array}$ & $\begin{array}{c}\text { Symmetrical } \\
\text { stretch of } \\
\text { apical Si-O bonds }\end{array}$ & $\begin{array}{c}\text { TO mode } \\
\text { frequency - } \\
\text { dipolar moment } \\
\text { to } a, b \text { plane }{ }^{c}\end{array}$ & $\begin{array}{l}\text { Degenerated } \\
\text { Si-O } \\
\text { stretching }\end{array}$ & $\begin{array}{c}\text { In-plane } \\
\text { displacement } \\
\text { of hydrogen }\end{array}$ & $\begin{array}{c}\text { Further } \\
\text { bands }\end{array}$ \\
\hline \multirow[t]{6}{*}{ LizZH1 RT } & 3700 & 1080 & 1045 & 964 & 614 & 560 \\
\hline & 3688 & & & & & \\
\hline & 3648 & & & & & \\
\hline & 3570 & & & & & \\
\hline & 3420 & & & & & \\
\hline & $\begin{array}{l}v_{3} \text { stretching of } \\
\mathrm{SiO}_{4}{ }^{\mathrm{d}}\end{array}$ & $\begin{array}{l}v_{1} \text { stretching of } \\
\mathrm{SiO}_{4}{ }^{\mathrm{d}}\end{array}$ & $\begin{array}{l}v_{4} \text { stretching of } \\
\mathrm{SiO}_{4}{ }^{\mathrm{d}}\end{array}$ & $\begin{array}{l}\text { Corresponding } \\
\text { hydroxyl gro }\end{array}$ & $\begin{array}{l}\text { to remaining } \\
\text { ups }\end{array}$ & \\
\hline \multirow{2}{*}{$\underset{\min }{\operatorname{LizZH} 1650{ }^{\circ} \mathrm{C} \text { for } 30}$} & 992 & 883 & 615 & 673 & & \\
\hline & 959 & 841 & & & & \\
\hline
\end{tabular}

$\mathrm{R} T$ - room temperature.

${ }^{\mathrm{a}}$ Fuchs et al. (1998).

${ }^{\mathrm{b}}$ Farmer (1974).

${ }^{\mathrm{c}}$ Balan et al. (2002).

dJeanloz (1980).

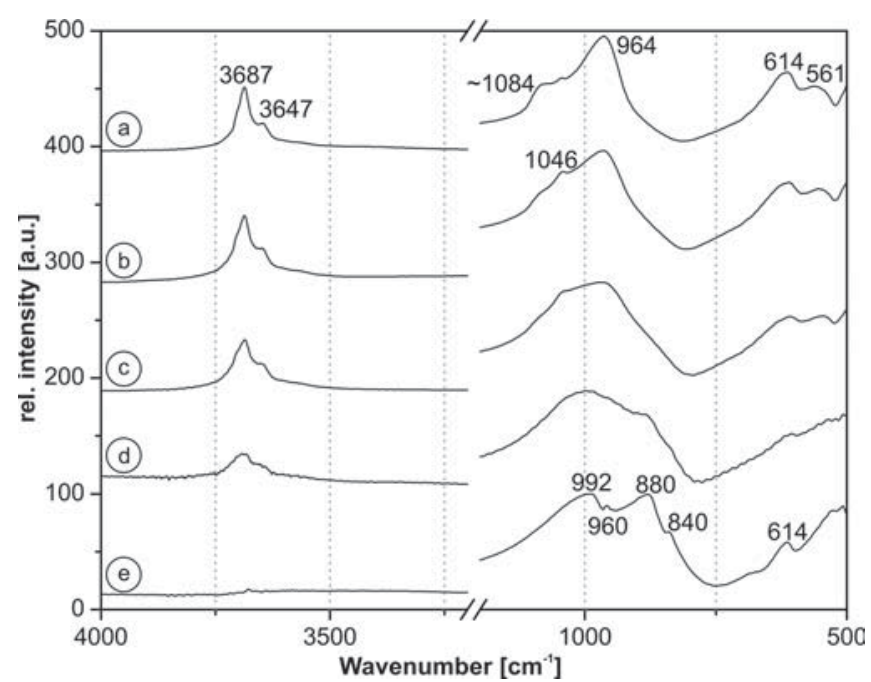

Fig. 6. Phase transformation of lizardite LizZH1 observed on thermally pre-treated powder samples by FTIR $\left(4000-500 \mathrm{~cm}^{-1}\right)$; a. 300 ${ }^{\circ} \mathrm{C}$ for $30 \mathrm{~min}$, b. $500{ }^{\circ} \mathrm{C}$ for $30 \mathrm{~min}$, c. $550{ }^{\circ} \mathrm{C}$ for $30 \mathrm{~min}, \mathrm{~d} .600{ }^{\circ} \mathrm{C}$ for $30 \mathrm{~min}$, e. $650{ }^{\circ} \mathrm{C}$ for $30 \mathrm{~min}$.

slightly lower values are found for experiments carried out under nitrogen atmosphere and with a slightly different particle size distribution (Table 2). Two corresponding ln-ln plots (Fig. 7 and 8) show the quality of the fitting procedure. The exponent $n$ is between 0.6 and 1.0 and has a tendency to increase with temperature (Table 2). These values are close to the results reported by Weber \& Greer (1965).

Model-free kinetic data obtained from isothermal runs treated by the "time to a given fraction" method highlight a strong $E_{a} v s$. reaction progress $(\alpha)$ dependency, i.e. mechanistic interpretations cannot be made on the basis of the Avrami method. The values for small reaction progress $(\alpha \leq 20 \%)$ are below $300 \pm 16 \mathrm{~kJ} / \mathrm{mol}$, and steadily increase to values between 340 and $350 \pm 8 \mathrm{~kJ} / \mathrm{mol}$ for reaction progress $\alpha>60 \%$. The poor fits in the $\ln t_{\alpha} v s .1 / T$ $\left[\mathrm{K}^{-1}\right]$ plots for small reaction progress reflect insufficient resolution in determination of the reaction progress with X-ray based methods (Fig. 9).

The activation energies as function of reaction progress for the milled particles obtained from a set of non-isothermal TGA experiments (Fig. 10) are characterised by an initial plateau with $E_{a} \approx 240(3) \mathrm{kJ} / \mathrm{mol}$, followed by an ascending part with small intermediate plateaus until a maximum of $370(4) \mathrm{kJ} / \mathrm{mol}$ is reached. At a more advanced stage of the reaction $E_{a}$ decreases gently to a final value of around 340(3) kJ/mol (Fig. 11). These data are compatible with the model-free isothermal data obtained from the TGF data (Fig. 8). Generally, variations in the pre-exponential factor $A$ follow the course of $E_{a}$ with $\alpha$. These results were reproduced in parallel experiments, although the local maxima in $E_{a}$, the intensity and position of stagnation plateaus are variable. Causes for such variations are slightly deviating starting conditions i.e. differences in the initial sample weights and differences in the particlesize distribution (Roduit et al., 1996). In general, error estimations base on mathematical treatments by Cai \& Chen (2009). The curve for the sieved sample is shifted to the right, i.e. show a delayed increase but reaches the same maximum values. There are also no intermediate plateaus visible.

\section{Discussion}

In a huge volume of literature on the kinetics of the dehydroxylation of phyllosilicates, data are typically treated by the Avrami or the TGF method and the activation energy and the "reaction order" is interpreted in a mechanistic way (e.g., Redfern, 1987; Bose \& Ganguly, 1994; Bellotto et al., 1995; Gualtieri et al., 1995; Bray \& Redfern, 1999; Mazzucato et al., 1999; Cattaneo et al., 2003; Tokiwai \& 
Table 2. Summary of calculated kinetic parameters for the dehydroxylation of lizardite (Avrami-Erofe'ev method).

\begin{tabular}{|c|c|c|c|c|c|c|}
\hline Sample & $T\left({ }^{\circ} \mathrm{C}\right)$ & $n$ & $R^{2}$ & $k$ & $A\left(\mathrm{~s}^{-1}\right)$ & $E_{a}(\mathrm{~kJ} / \mathrm{mol})$ \\
\hline \multirow[t]{7}{*}{ LizZH1 milled (air) } & 600 & $0.937(2)$ & 0.9962 & $1.28(1) \times 10^{-3}$ & $8.9(4) \times 10^{17}$ & $347 \pm 16$ \\
\hline & 610 & $0.903(4)$ & 0.9922 & $2.24(1) \times 10^{-3}$ & & \\
\hline & 620 & $0.978(2)$ & 0.9956 & $5.45(1) \times 10^{-3}$ & $R^{2}=0.9836$ & \\
\hline & 630 & $0.970(4)$ & 0.9918 & $7.89(3) \times 10^{-3}$ & & \\
\hline & 640 & $0.941(4)$ & 0.9908 & $1.28(1) \times 10^{-2}$ & & \\
\hline & 650 & $0.91(1)$ & 0.9713 & $1.79(3) \times 10^{-2}$ & & \\
\hline & 660 & $1.025(7)$ & 0.9866 & $2.86(2) \times 10^{-2}$ & & \\
\hline \multirow[t]{7}{*}{ LizZH1 milled $\left(\mathrm{N}_{2}\right)$} & 600 & $0.634(1)$ & 0.9961 & $1.14(1) \times 10^{-3}$ & $5.7(4) \times 10^{16}$ & $326 \pm 22$ \\
\hline & 610 & $0.592(2)$ & 0.9942 & $4.07(1) \times 10^{-3}$ & & \\
\hline & 620 & $0.686(3)$ & 0.9912 & $4.39(2) \times 10^{-3}$ & $R^{2}=0.9365$ & \\
\hline & 630 & $0.771(5)$ & 0.9863 & $9.64(6) \times 10^{-3}$ & & \\
\hline & 640 & $0.779(3)$ & 0.9932 & $1.38(1) \times 10^{-2}$ & & \\
\hline & 650 & $0.868(7)$ & 0.9833 & $1.49(1) \times 10^{-2}$ & & \\
\hline & 660 & $0.928(7)$ & 0.9841 & $2.91(2) \times 10^{-2}$ & & \\
\hline \multirow[t]{7}{*}{ LizZH1 sieved (air) } & 600 & $0.739(6)$ & 0.9848 & $1.51(1) \times 10^{-3}$ & $3.1(2) \times 10^{16}$ & $323 \pm 14$ \\
\hline & 610 & $0.862(8)$ & 0.9825 & $2.20(2) \times 10^{-3}$ & & \\
\hline & 620 & $0.726(5)$ & 0.9873 & $3.85(3) \times 10^{-3}$ & $R^{2}=0.9877$ & \\
\hline & 630 & $0.867(6)$ & 0.9866 & $8.33(5) \times 10^{-3}$ & & \\
\hline & 640 & $0.974(3)$ & 0.9929 & $1.04(1) \times 10^{-2}$ & & \\
\hline & 650 & $0.927(3)$ & 0.9929 & $1.56(1) \times 10^{-2}$ & & \\
\hline & 660 & $0.992(3)$ & 0.9947 & $2.51(1) \times 10^{-2}$ & & \\
\hline
\end{tabular}

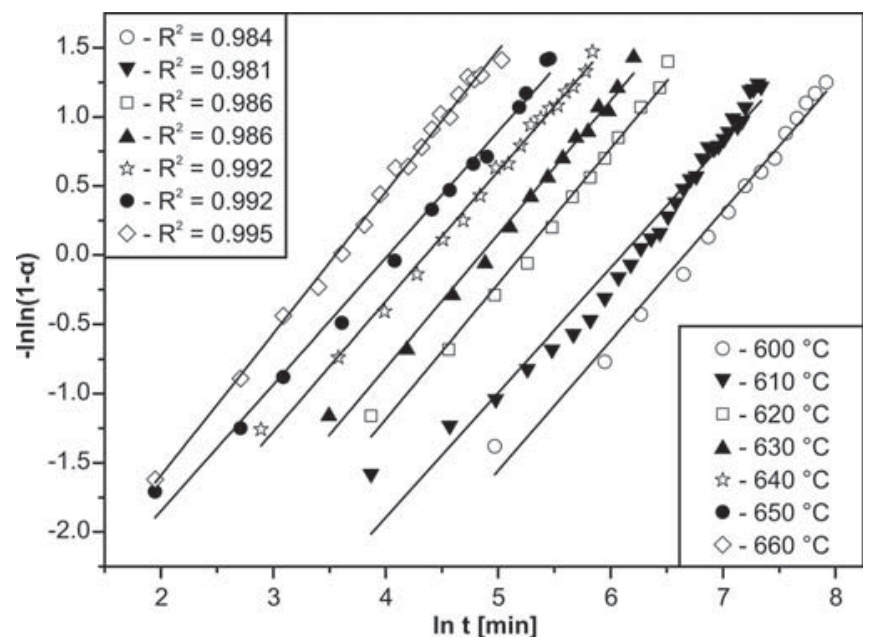

Fig. 7. $\ln -\ln$ plot of HT-XRD runs on LizZH1 milled.

Nakashima, 2010). This procedure, however, is only strictly valid for reactions for which the rate- determining step does not change with reaction progress. The TGF and non-isothermal results clearly show that this is not the case for the dehydroxylation of lizardite. A similar conclusion has probably to be drawn also for other phyllosilicates, and for most other solid-state reactions (e.g., Vyazovkin \& Wight, 1997; Galwey \& Brown, 2002; Vyazovkin, 2008). Non-isothermal experiments will readily show if the kinetics of a reaction are truly controlled by a single reaction step. Many authors present the kinetics-derived mechanistic aspects of the reactions alone, without complementary support from spectroscopic or microscopic data (Raman, FTIR, X-ray based structural refinements,

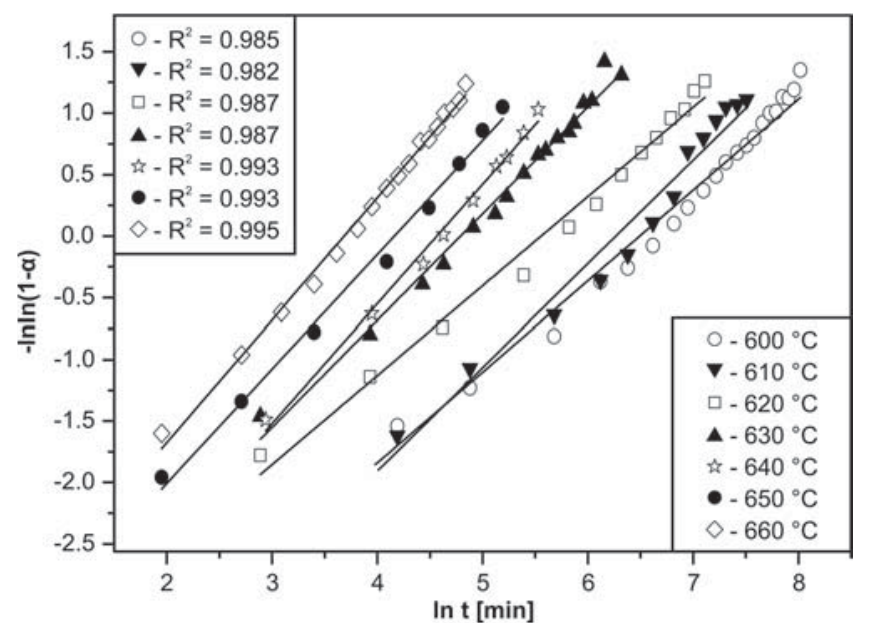

Fig. 8. ln-ln plot of HT-XRD runs on LizZH1 sieved.

TEM) or from $a b$ initio calculation to support their interpretations.

Classical isothermal and non-isothermal heating experiments of lizardite clearly reveal a multi-step dehydroxylation mechanism for which the activation energy and, therefore, also the rate-determining step changes with reaction progress (Fig. 11). To interpret mechanisms as a function of reaction progress we need to know how many parallel or sequential reaction steps are controlling the rate at any instant of the entire reaction duration. Afterwards, observed values could be compared with activation energies available for certain reaction steps. Such data have been obtained from $a b$ initio quantum mechanical calculation (DFT models) for the dioctahedral phyllosilicate 


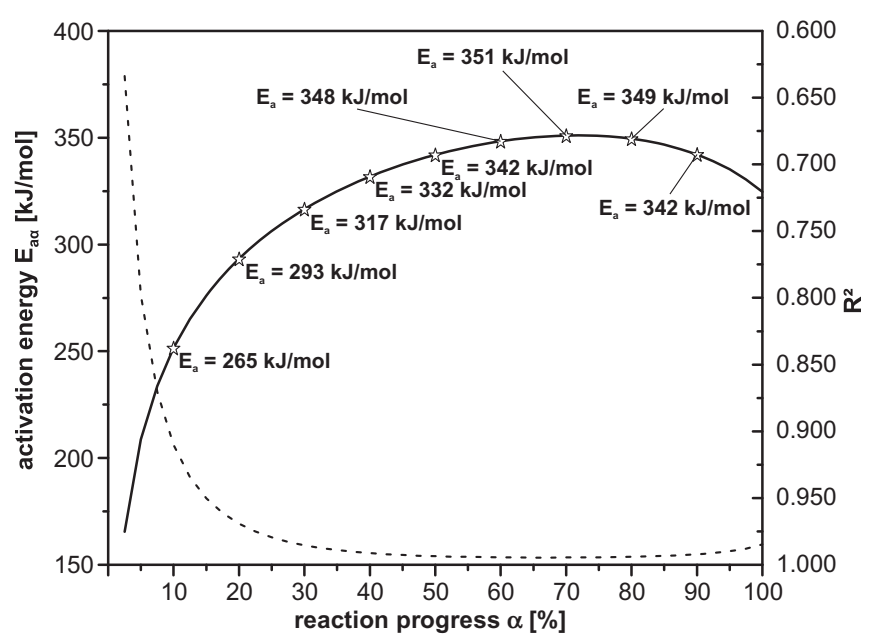

Fig. 9. Results of the time-to-a-given-fraction method showing $E_{a}$ as function of the reaction progress $\alpha$.

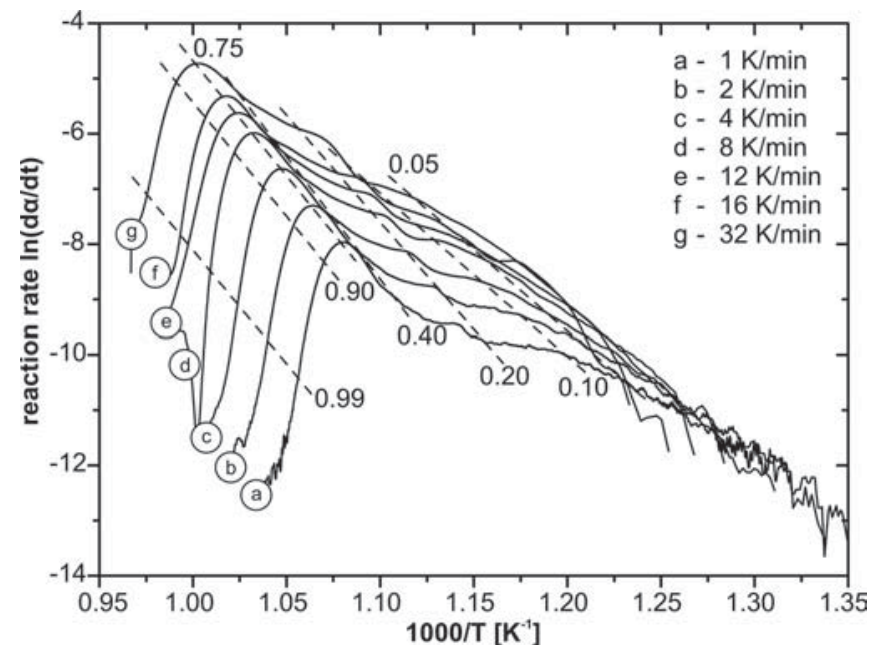

Fig. 10. Reaction rate $\ln (\mathrm{d} \alpha / \mathrm{d} t)$ as a function of the inverse absolute temperature for seven individual TGA runs.

pyrophyllite (Molina-Montes et al., 2008a and b). The DFT models show that the reaction of adjacent hydroxyl groups to water molecules seem to be the rate-determining step in the initial stage of dehydroxylation of pyrophyllite (Molina-Montes et al., 2008a and b) and kaolinite (White et al., 2010). The reaction is favoured by reorientation of hydroxyl groups and direct transfer of the hydrogen to the adjacent hydroxyl without proton diffusion (Stackhouse et al., 2004). Because there are structurally different hydroxyl groups with different intermolecular distances it is not surprising that different rates and activation energies are obtained in the DFT calculations for the different recombination possibilities. Initially, the reaction between closest hydroxyl groups is predominant. With increasing reaction progress the recombinations involving more distant hydroxyl groups become more important. For such a

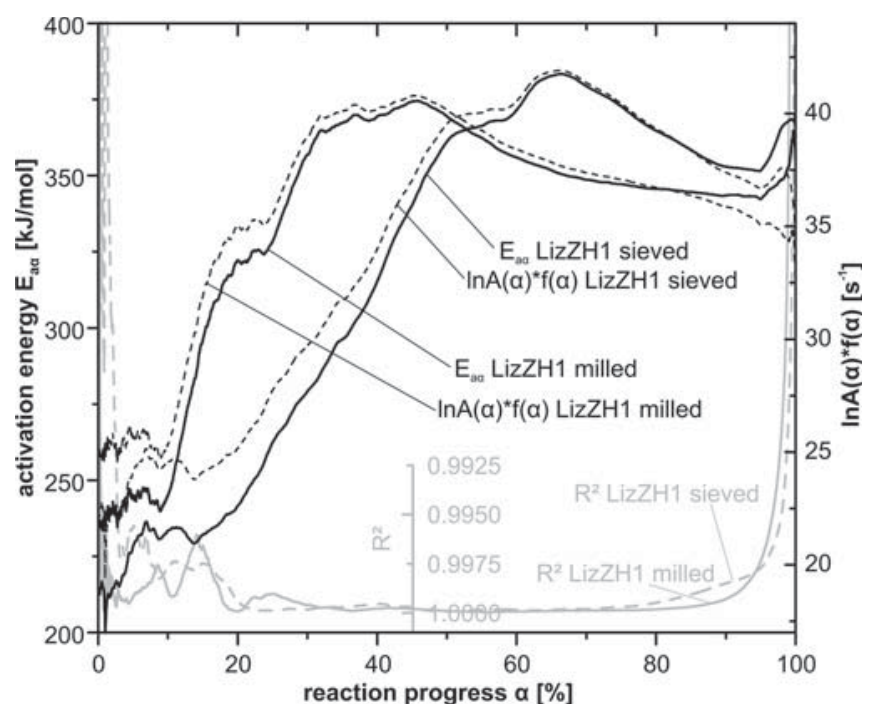

Fig. 11. Calculated activation energy $E_{a}$ as function of the reaction progress (isoconversional Friedman method), errors are smaller than the used line thickness.

scenario, the activation energy obtained from non-isothermal heating experiments, which is an average of the weighted activation energies of the individual recombination reactions (Vyazovkin, 2008), will change. As exemplarily outlined for lizardite, such a change can result in increasing activation energies.

The decrease of intensity of the $\mathrm{Mg}-\mathrm{OH}$ infrared bands, which begins earlier and is faster than for the $\mathrm{Si}-\mathrm{O}$ bands also indicate that the octahedral layer in lizardite is affected first and that most likely the recombination of $\mathrm{OH}$ groups and the formation of water molecules are dominant in the onset of the dehydroxylation reaction. According to McKelvy et al. (2006), the survival of the tetrahedral layer at the beginning of the reaction also explains the appearance of the $7.4^{\circ} 2 \Theta \mathrm{XRD}$ peak, which is an indicator for an intermediate phase similar to that observed during the thermal transformation of chrysotile (MacKenzie \& Meinhold, 1994). Assuming that the waterforming reaction is the initial rate-determining step, there are six nearest hydroxyl group pairs (Fig. 12). For the closest of them, the recombination is possible without an intervening diffusion step. It is obvious that all recombination possibilities may occur simultaneously, but the contributions of each step to the overall reaction rate will change with reaction progress, leading to the observed increase of the activation energy. In pyrophyllite the activation energies for calculated individual steps range from around 150 to $250 \mathrm{~kJ} / \mathrm{mol}$ (Stackhouse et al., 2004; Molina-Montes et al., 2008a and b), which match the minimum and maximum values observed in lizardite quite well considering the chemical and structural differences between both phyllosilicates.

On the basis of IR spectroscopic data, Zhang et al. (2010) suggest that the reaction between the hydroxyl groups in phyllosilicates does not inevitably lead to the formation of a water but of a $\mathrm{H}_{2}$ molecule, which diffuses 

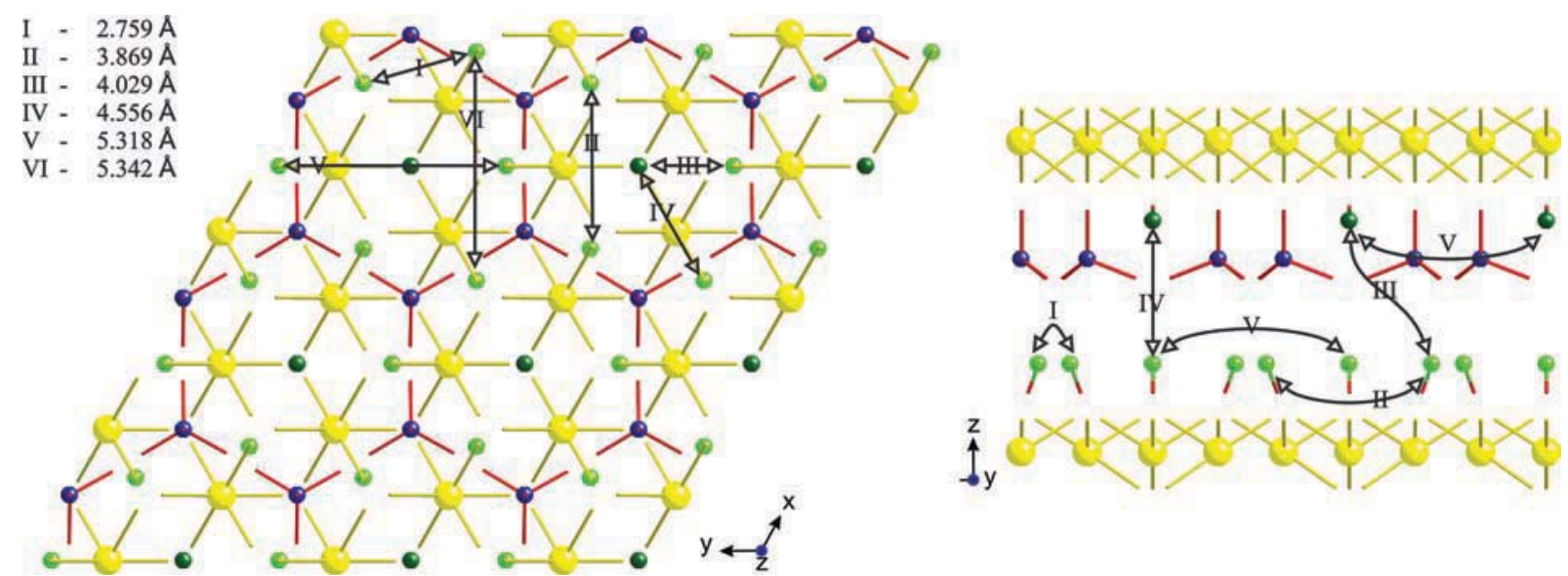

Fig. 12. Six possible recombination possibilities of adjacent hydroxyl groups within the crystal structure of lizardite 1T (Mellini, 1982) with respect to their proton distances $\left(T=25^{\circ} \mathrm{C}\right)$; yellow $-\mathrm{Mg}$, dark blue $-\mathrm{Si}$, light green $-\mathrm{H} 3$, dark green $-\mathrm{H} 4$, red bonds $-\mathrm{Si}-\mathrm{O}$ bonds, yellow bonds $-\mathrm{Mg}-\mathrm{O}$ bonds, red-green bonds $-\mathrm{OH}$ groups, arrows representing hydroxyl group interactions.

to the surface where it reacts with oxygen. Although not explored by the DFT calculations, such a reaction scenario would not change the fact that different recombinations are possible between hydrogen atoms, all with different probability of occurrence and activation energy. Already Martens et al. (1976) have successfully demonstrated the release of hydrogen and atomic oxygen during the dehydroxylation of brucite under controlled vacuum conditions. Therefore, similar reactions could also occur in complex phyllosilicates.

The recombination scheme presented in Fig. 12 does not take into account possible structural changes in the local structure due to the loss of a certain hydroxyl group. Such structural readjustments are to be expected and make a simple description of the individual reaction step difficult. Positive or negative "feedback loops" initiated by local structural changes may affect the number of interaction possibilities of hydroxyl groups and may also be responsible for changes in the activation energy of individual rate-determining steps. Recent ab initio calculations concerning the dehydroxylation of phyllosilicates (e.g., Stackhouse et al., 2004; Molina-Montes et al., 2008a,b; White et al., 2010) have not yet included such changes, as they used a rigid structure model except for the reacting atoms.

In non-isothermal experiments, both structural readjustments due to reaction progress and also structural changes due to the increase in temperature will affect reaction rates. Intramolecular distances $\mathrm{H} \cdots \mathrm{OH}$ are not fixed but change with temperature (Gregorkiewitz et al., 1996; Guggenheim \& Zhan, 1998). Consequently, the temperature dependency of the activation energy of an individual reaction step will not only be controlled by vibrational, but also by geometrical factors.

A last assumption inherently made when applying Avrami or TGF type models to describe kinetic data is that the reaction progress is the same across the entire sample. For powdered samples this may be true as long as all particles have the same size but, for polydisperse powders, surface effects will significantly influence the decomposition kinetics (Vyazovkin \& Wight, 1997).

\section{Concluding remarks}

This study has shown that complex multi-step dehydroxylation processes in lizardite cannot adequately be described by the Avrami-Erofe'ev method, which is limited to homogeneous reactions. Solid-state transformations are characterised by multiple parallel and sequential processes/reaction steps and the control of the reaction rate may change in the course of the reaction. Neither isothermal kinetic experiments over a limited temperature range nor non-isothermal experiments alone are sufficient to extract physical information of complex reaction mechanisms. Thus, the interpretation of the physical meaning of rate parameters is very limited for such solid-state reactions. Therefore, kinetic dehydroxylation studies of complex solid-state phases should be accompanied and supported by data from the field of spectroscopy, electron microscopy and/or ab initio calculations in order to make inferences on mechanisms.

Acknowledgements: The authors would like to thank Sophie Gomez and Jean-Nicolas Aebischer (College of engineering and architecture, Fribourg) for the use and support of analytical and software infrastructure, Christoph Neururer and Jean-Paul Bourqui (both University of Fribourg) for their technical support, Martin Robyr (University of Bern) for the EMPA support, Mehdi Salehi (EMPA Duebendorf/Switzerland) for performing the particle size analysis and Bertrand Roduit (AKTS AG/Sierre) for methodological discussions and the allowance to use the AKTS Thermokinetics software package. This study was founded by the Swiss National Science Foundation (grant 200021-121964). 


\section{References}

Avrami, M. (1939): Kinetics of phase change I - general theory. J. Chem. Phys., 7, 1103-1112.

Avrami, M. (1940): Kinetics of phase change II - transformationtime relations from random distribution of nuclei. J. Chem. Phys., 8, 212-224.

Avrami, M. (1941): Granulation, phase change, and microstructure kinetics of phase change III. J. Chem. Phys., 9, 177-184.

Balan, E., Saitta, A.M., Mauri, F., Lemaire, C., Guyot, F. (2002): First-principles calculation of the infrared spectrum of lizardite. Am. Mineral., 87, 1286-1290.

Bamford, C.H. \& Tipper, C.F.H. (1980): Comprehensive chemical kinetics. Vol. 22, Reactions in the solid state. Elsevier, Amsterdam, Oxford, New York, 340 p.

Bellotto, M., Gualtieri, A., Artioli, G., Clark, S.M. (1995): Study of the kaolinite-mullite reaction sequence. Part I: kaolinite dehydroxylation. Phys. Chem. Minerals, 22, 207-214.

Bose, K. \& Ganguly, J. (1994): Thermogravimetric study of the dehydration kinetics of talc. Am. Mineral., 79, 692-699.

Bray, H. \& Redfern, S.A.T. (1999): Kinetics of dehydration of Camontmorillonite. Phys. Chem. Minerals, 26, 591-600.

Brigatti, M.F., Galli, E., Medici, L., Poppi, L. (1997): Crystal structure refinement of aluminian lizardite $2 \mathrm{H}_{2}$. Am. Mineral., 82, 931-935.

Brindley, G.W. \& Hayami, R. (1963a): Kinetics and mechanisms of dehydration and recrystallization of serpentine-1. Clays Clay Minerals, 12, 35-47.

_, - (1963b): Kinetics and mechanisms of dehydration and recrystallization of serpentine-2, Spectrum of activation energies for recrystallization. Clays Clay Minerals, 12, 49-54.

Burke, J. (1965): The kinetics of phase transformation in metals. Pergamon Press Inc, Oxford, $226 \mathrm{p}$.

Cai, J. \& Chen, S. (2009): A new iterative linear integral isoconversional method for the determination of the activation energy varying with the conversion degree. J. Comput. Chem., 30, 1986-1991.

Cattaneo, A., Gualtieri, A.F., Artioli, G. (2003): Kinetic study of the dehydroxylation of chrysotile asbestos with temperature by in situ XRPD. Phys. Chem. Minerals, 30, 177-183.

Dódony, I. \& Buseck, P.R. (2004): Serpentines close-up and intimate: an HRTEM view. Int. Geol. Rev., 46, 507-527.

Erofe'ev, B.V. (1946): Generalized equation of chemical kinetics and its application in reactions involving solids. Dokl. Akad. Nauk. SSSR+, 52, 511-514.

Farmer, V.C. (1974): The layer silicates. in "The infra-red spectra of minerals", V.C., Farmer, ed., Mineralogical Society, London, 331-363.

Friedman, H.L. (1964): Kinetics of thermal degradation of charforming plastics from thermogravimetry. Application to phenolic plastic. J. Polym. Sci. Pol. Sym., 6, 183-195.

Fuchs, Y., Linares, J., Mellini, M. (1998): Mössbauer and infrared spectrometry of lizardite-1T from Monte Fico, Elba. Phys. Chem. Minerals, 26, 111-115.

Galwey, A.K. (2004): Is the science of thermal analysis kinetics based on solid foundations? A literature appraisal. Thermochim. Acta, 413, 139-183.

Galwey, A.K. \& Brown, M.E. (2002): Application of the Arrhenius equation to solid state kinetics: can this be justified? Thermochim. Acta, 386, 91-98.
Gregorkiewitz, M., Lebech, B., Mellini, M., Viti, C. (1996): Hydrogen positions and thermal expansion in lizardite $1 T$ from Elba: a low-temperature study using Rietveld refinement of neutron diffraction data. Am. Mineral., 81, 1111-1116.

Gualtieri, A.F. \& Tartaglia, A. (2000): Thermal decomposition of asbestos and recycling in traditional ceramics. J. Eur. Ceram. Soc., 20, 1409-1418.

Gualtieri, A., Bellotto, M., Artioli, G., Clark, S.M. (1995): Kinetic study of the kaolinite-mullite reaction sequence. Part II: mullite formation. Phys. Chem. Minerals, 22, 215-222.

Guggenheim, S. \& Zhan, W. (1998): Effect of temperature on the structures of lizardite $1 T$ and lizardite $2 H_{1}$. Can. Mineral., 36, 1587-1594.

Hancock, J.D. \& Sharp, J.H. (1972): Method of comparing solidstate kinetic data and its application to decomposition of kaolinite, brucite, and $\mathrm{BaCO}_{3}$. J. Am. Ceram. Soc., 55, 74-77.

Jeanloz, R. (1980): Infrared spectra of olivine polymorphs $-\alpha, \beta$ phase and spinel. Phys. Chem. Mineral., 5, 327-341.

Johnson, W.A. \& Mehl, R.F. (1939): Reaction kinetics in processes of nucleation and growth. T. Am. I. Min. Met. Eng., 135, 416-458.

Jolicoeur, C. \& Duchesne, D. (1981): Infrared and thermogravimetric studies of the thermal-degradation of chrysotile asbestos fibers - evidence for matrix effects. Can. J. Chem., 59, $1521-1526$.

MacKenzie, K.J.D. \& Meinhold, R.H. (1994): Thermal reactions of chrysotile revisited: a ${ }^{29} \mathrm{Si}$ and ${ }^{25} \mathrm{Mg}$ MAS NMR study. $\underline{\mathrm{Am}}$. Mineral., 79, 43-50.

Martens, R., Gentsch, H., Freund, F. (1976): Hydrogen release during thermal decomposition of magnesium hydroxide to magnesium oxide. J. Catal., 44, 366-372.

Mazzucato, E., Artioli, G., Gualtieri, A. (1999): High temperature dehydroxylation of muscovite- $2 M_{I}$ : a kinetic study by in situ XRPD. Phys. Chem. Minerals, 26, 375-381.

McKelvy, M.J., Chizmeshya, A.V.G., Diefenbacher, J., Bearat, H., Wolf, G. (2004): Exploration of the role of heat activation in enhancing serpentine carbon sequestration reactions. Environ. Sci. Technol., 38, 6897-6903.

McKelvy, M.J., Sharma, R., Chizmeshya, A.V.G. (2006): Lamellar reaction phenomena: from intercalation to nanomaterials formation. J. Phys. Chem. Solids, 67, 888-895.

Mellini, M. (1982): The crystal structure of lizardite $1 T$ : hydrogen bonds and polytypism. Am. Mineral., 67, 587-598.

Mellini, M. \& Zanazzi, P.F. (1987): Crystal structures of lizardite $1 T$ and lizardite $2 H_{l}$ from Coli, Italy. Am. Mineral., 72, 943-948.

Molina-Montes, E., Donadio, D., Hernández-Laguna, A., SainzDíaz, C.I. (2008a): DFT research on the dehydroxylation reaction of pyrophyllite - 2. Characterization of reactants, intermediates, and transition states along the reaction path. J. Phys. Chem. A, 112, 6373-6383.

Molina-Montes, E., Donadio, D., Hernández-Laguna, A., Sainz-Díaz, C.I., Parrinello, M. (2008b): DFT research on the dehydroxylation reaction of pyrophyllite 1 . First-principle molecular dynamics simulations. J. Phys. Chem. B, 112, 7051-7060.

Redfern, S.A.T. (1987): The kinetics of dehydroxylation of kaolinite. Clay Minerals, 22, 447-456.

Roduit, B., Maciejewski, M., Baiker, A. (1996): Influence of experimental conditions on the kinetic parameters of gas-solid reactions - parametric sensitivity of thermal analysis. Thermochim. Acta, 283, 101-119. 
Seber, G.A.F. \& Wild, C.J. (1989): Nonlinear Regression. John Wiley \& Sons, New York, 768 p.

Stackhouse, S., Coveney, P.V., Benoit, D.M. (2004): DensityFunctional-Theory-based study of the dehydroxylation behavior of aluminous dioctahedral 2:1 layer-type clay minerals. J. Phys. Chem. B, 108, 9685-9694.

Tokiwai, K. \& Nakashima, S. (2010): Dehydration kinetics of muscovite by in situ infrared microspectroscopy. Phys. Chem. Mineral., 37, 91-101.

Ulmer, P. \& Trommsdorff, V. (1995): Serpentine stability to mantle depths and subduction-related magmatism. Science, 268, 858-861.

Viti, C. (2010): Serpentine minerals discrimination by thermal analysis. Am. Mineral., 95, 631-638.

Vyazovkin, S. (2000): Computational aspects of kinetic analysis. Part C. The ICTAC kinetics project - the light at the end of the tunnel? Thermochim. Acta, 355, 155-163.

Vyazovkin, S. (2008): Isoconversional kinetics. in "Handbook of thermal Analysis and Calorimetry”, M.E. Brown \& P.K. Gallagher, eds., Elsevier, Amsterdam, Oxford, New York, 503-538.
Vyazovkin, S. \& Wight, C.A. (1997): Kinetics in solids. Annu. Rev. Phys. Chem., 48, 125-149.

Weber, J.N. \& Greer, R.T. (1965): Dehydration of serpentine - heat of reaction and reaction kinetics at $\mathrm{P}_{\mathrm{H} 2 \mathrm{O}}=1 \mathrm{~atm}$. Am. Mineral., 50, 450-464.

White, C.E., Provis, J.L., Proffen, T., Riley, D.P., van Deventer, J.S.J. (2010): Density functional modeling of the local structure of kaolinite subjected to thermal dehydroxylation. J. Phys. Chem. A, 114, 4988-4996.

Zema, M., Ventruti, G., Lacalamita, M., Scordari, F. (2010): Kinetics of Fe-oxidation/deprotonation process in Fe-rich phlogopite under isothermal conditions. Am. Mineral., 95, 1458-1466.

Zhang, M., Redfern, S.A.T., Salje, E.K.H., Carpenter, M.A., Wang, L. (2010): $\mathrm{H}_{2} \mathrm{O}$ and the dehydroxylation of phyllosilicates: an infrared spectroscopic study. Am. Mineral., 95, 1686-1693. 